\title{
Freud with Charcot: Freud's discovery and the question of diagnosis
}

\author{
Thomas Lepoutre ${ }^{\mathrm{a}}$ and François Villa ${ }^{\mathrm{b}}$ \\ ${ }^{a}$ Centre for Research on Psychoanalysis, Medicine and Society (CRPMS, \\ EA 3522), Paris Diderot University at Sorbonne Paris Cité - thomaslepou \\ tre@free.fr \\ ${ }^{b}$ Full Professor of Psychopathology, Centre for Research on Psychoanal- \\ ysis, Medicine and Society (CRPMS, EA 3522), Paris Diderot University \\ at Sorbonne Paris Cité, Member of the Association Psychanalytique de \\ France-villa@univ-paris-diderot.fr
}

(Accepted for publication 1 May 2014)

\begin{abstract}
Although Charcot's seminal role in influencing Freud is widely stated, although Freud's trip to Paris to study with Charcot is well recognized as pivotal in his shift from neurological to psychopathological work, a key fact of the Freudian heuristic remains largely underestimated: namely, that Freud's psychopathological breakthrough, which gave birth to psychoanalysis, cannot be separated from his 'diagnostic preoccupation', which is a crucial and at times the first organizing principle of his earliest writings. The purpose of this article is therefore to reopen the question of diagnosis by following its development along the path leading from Charcot to Freud. The authors demonstrate that Freud's careful attention to diagnostic distinctions follows strictly in the direction of Charcot's 'nosological method'. More importantly, the article intends to identify the precise way in which his ideas operate in Freud's own work, in order to understand how Freud reinvests them to forge his own nosological system. If the authors trace the destiny of Charcot's lessons as they reach Freud's hands, it is the importance granted to mixed neuroses in Freud's psychopathology that allows them to pinpoint the role played by the diagnostic process in the rationality of psychoanalysis.
\end{abstract}

Keywords: diagnosis, nosography, Charcot, methodology, mixed neuroses

German, as well as English, authorities are still in the habit today of allotting the descriptions 'hysteria' and 'hysterical' capriciously, and of throwing 'hysteria' into a heap along with general nervousness, neurasthenia, many psychotic states and many neuroses which have not yet been picked out from the chaos of nervous diseases. Charcot, on the contrary, holds firmly to the view that 'hysteria' is a sharply circumscribed and well-defined clinical picture, which may be most clearly recognized in the extreme cases of what is known as 'grande hystérie' [major hysteria] (or hystero-epilepsy) [...]. Hysteria is fundamentally different from neurasthenia and indeed, strictly speaking, is contrary to it.

(Freud, 1888, pp. 40-1)

In the aforementioned quotation, Freud clearly designates one of the starting points of his research: the moment when a highly specific and 
"well-defined clinical picture" begins to emerge from "the chaos of nervous diseases". At the time of the beginning of psychoanalysis, the picture of hysteria is actually suitably characterized to be easily recognized in the clinical practice and, at the same time, its most extreme forms (the so-called grande hystérie) are sufficiently expressive for Freud to be able to decipher their meaning.

Hence, nosographic definition and diagnostic identification go hand in hand with the liberation of speech; this is the meaning of a gesture that Freud himself attributes to Charcot (despite the latter's stubborn blindness to questions of psychology):

The first thing that Charcot's work did was to restore its dignity to the topic. Little by little, people gave up the scornful smile with which the patient could at that time feel certain of being met. She was no longer necessarily a malingerer, for Charcot had thrown the whole weight of his authority on the side of the genuineness and objectivity of hysterical phenomena. Charcot had repeated on a small scale the act of liberation in memory of which Pinel's portrait hung in the lecture hall of the Salpêtrière.

(Freud, 1893, p. 19)

Rereading Freud allows us to appreciate this key factor of his work: the fact that Charcot's diagnostic method was a major stimulus to Freud's own discovery. Given this state, we argue that there is an important need to reexamine the influence Charcot's diagnostic method had on Freud's discovery.

Indeed, although Charcot's seminal role in influencing Freud is widely stated, although Freud's trip to Paris to study with Charcot is well recognized as "pivotal in his shift from neurological and physiological to psychopathological work" (Miller et al., 1969, p. 608), a key fact of the Freudian heuristic remains largely underestimated: namely, that Freud's psychopathological breakthrough leading to psychoanalysis, cannot be separated from his "diagnostic preoccupation", which is a crucial and at times the first organizing principle of his earliest writings. The purpose of this article is therefore to re-open the question of diagnosis by following its development along the path leading from Charcot to Freud.

Such an historical study can be justified by the current debate regarding the kind of role that diagnosis play in the analytic field, a debate which is still being discussed within the psychoanalytic community (see, for example, the reports of panels on 'the importance of psychoanalytic diagnosis in clinical work' held at the 47th Congress of the International Psychoanalytic Association in Mexico City, in Altman et al, 2012).

In fact, the psychoanalytic community today frequently appears to be divided between, on the one hand, the analysts who question the importance of diagnostic appreciation, underlying that more often than not the diagnosis is never reducible to one well-defined category, and that, since the transference is always the final arbiter, the analyst has little or nothing to do with diagnosis (except to deliver the first indication for therapy); and, on the other hand, those who believe that psychoanalysis on the contrary has to be much more rigorous on nosological definitions and diagnostic 
issues, and should therefore adopt a neopositivistic paradigm to improve the existing diagnostic systems by considering the deep structural foundations of personality.

To some extent, it appears that this divide between two extreme positions towards diagnostic issues is to be superimposed on:

\begin{abstract}
this divide between two cultures in psychoanalysis [that] also reflects in some cases a tension between idiographic and nomothetic approaches toward science, with the former approach interested mainly in understanding individuals and their particular, idiosyncratic history, beliefs, and behaviors, the latter being focused on discovering lawful regularities across individuals.
\end{abstract}

(Luyten et al., 2006)

But before taking up a premature position into this debate, is it not relevant to put first such a simple question: what exactly was Freud's complex position toward diagnostic issues? Where, in point of fact, does Freud stand in the debate?

The lasting importance of this major concern in Freud's work is therefore interesting both historically and in relation to the psychoanalytic method as it is practised today. In Freud's work, we indeed find that the question of diagnosis is constantly on his mind. The numerous proofs of this concern by far exceed the dimension of the anecdotal, of the story of Freud's life as a physician driven by a desire for knowledge. They are therefore radically at odds with the suspicion that we commonly see in today's psychoanalysts' attitude towards questions of nosography.

Contrary to this topos of contemporary psychoanalytic literature, we would therefore like to retrace Freud's steps and show that the method now bearing his name only came into existence through a series of "nosographic innovations" (Freud, 1896a) following his encounter with Charcot, as well as through Freud's constant effort of "making a sharp distinction between the clinical pictures of the various neuroses" (Breuer and Freud, 1895, p. 256).

The main purpose is to show that Freud's careful attention to diagnostic distinctions, which we see even before the advent of psychoanalysis, follows strictly in the direction of Charcot's 'nosological method'. We would therefore like to re-emphasize the latter's influence but, more importantly, we wish to identify the precise way in which his ideas operate in Freud's own work, in order to understand how Freud reinvests them to forge his own nosological system.

The fact of the matter is that Freud believed that if the "purely nosographic" description of the Salpêtrière School precluded any theoretical explanation of the phenomena in question, it is because it had not been taken far enough: "[Charcot] did not make a sufficiently sharp distinction between organic nervous affections and neuroses, either as regards their aetiology or in other respects" (Freud, 1893, p. 22). To understand Freud's argument seriously, we need to consider that in the early 1890s he set to work precisely in the field of nosography where Charcot has previously distinguished himself. This concern is remarkably well expressed in the titles of at least two of Freud's major papers of this time: Some points for a 
comparative study of organic and hysterical motor paralyses, which the young Freud wrote shortly after his experience at the Salpêtrière, and later $O n$ the grounds for detaching a particular syndrome from neurasthenia under the description 'anxiety neurosis'. Both of them show that most of his efforts aimed at a differential description of the still largely chaotic field of nervous diseases. After Freud helped to establish the distinctions Charcot promoted, during the period of 1894-1896, he focused on dissecting the field of the yet undifferentiated phenomena, thus introducing a strong diagnostic predilection into the heart of what in the meantime had become his own practice. Whether we are speaking of neurasthenia or anxiety neurosis, about phobias or obsessional neuroses, about hysteria or epilepsy, psychoneuroses or actual neuroses, Freud's breakthrough work in the psychopathology of nervous disease necessarily involves deconstructing the clinical pictures in question. He formulates this imperative right at the beginning, when he points out that: "We have still to await the directing hand which shall set up boundary-marks in the region of the commonly occurring mixed neuroses and which shall bring out the features essential for their characterization" (1895, p. 84).

This is precisely why our article would like to reopen this 'chapter' of the origins of psychoanalysis and re-examine some of Freud's early arguments concerning the field of the neuroses, in order to show the extent to which his 'directing hand' has been influenced by a particular aspect of Charcot's methodology and thus to identify the role played by diagnosis in Freud's own discovery.

But let us be clear: we are not simply using the figure of Charcot to access Freud's origins because, from a purely historical point of view, this original truth is something worth remembering. Our main motive is that Freud continued to confront the question of diagnosis, explicitly and repeatedly, in order to situate, from an epistemological point of view, his own research within the larger field of medicine. ${ }^{1}$ Our aim is then to ascertain its heuristic status in the development of Freud's work, as well as its methodological importance for clinical practice. We hope thus to get a better understanding of the analytical method itself. Moreover, as already noted, we think that the Freudian attitude toward diagnostic issues actually gains at being reminded in the context of modern psychoanalytic research (Fonagy et al., 2002), and needs to be put in perspective with the current question relating to the value of diagnosis in our field - as it can be raised, for example, by the publication of new psychodynamic-oriented diagnostic manuals, like the Psychodynamic Diagnostic Manual (PDM Task Force, 2006) and the $O P D-2$ (Arbeitskreis OPD, 2006).

\section{Psychoanalysis and the question of diagnosis}

In order to properly reintroduce the question of diagnosis in psychoanalysis, let us make a quick etymological remark: to diagnose, which comes

\footnotetext{
${ }^{1}$ Our research at the Centre de Recherches Psychanalyse, Médecine et Société has been focusing on these questions and their present-day relevance for precisely these reasons.
} 
from the Greek diagnôstikein, essentially means 'being able to discern' or 'to recognize'. In any diagnostic approach, the question is literally of 'discernment'; we are always trying to identify or differentiate in relation to clinical experience, through a double operation of recognition and discrimination. We are always looking for what is common and what is different: making a diagnosis means including a case in a given series, or excluding it from it. The expression 'differential diagnosis' is therefore, strictly speaking, a pleonasm because there can be no positive judgement without separation, without discrimination and delimitation; we cannot recognize what is unless we simultaneously articulate what is not. In other words, any positive recognition is already a 'differential diagnosis'.

It is worth noticing that Freud felt the need to point out this fundamental imperative of diagnosis, i.e. that only by differentiating well enough between the cases we can grasp their specificity, and its key importance for his own field precisely when he is speaking about the "secessionist movements which have been so frequent in the history of analysis" (Freud, 1933, p. 139). Referring to the concrete case of "Adler's 'Individual Psychology" and in order to condemn the "commonplace truth" of its author's aetiological hypotheses, it seems as if Freud was taking this opportunity to declare, $a$ contrario, the deep affinity between properly psychoanalytic reasoning and the need for diagnostic distinction. The famous anecdote features a physician, who is essentially too aware of the demand his patients place on his irreproachable knowledge to respond to them on a case-to-case basis:

He told me that his medical practice proceeded as follows. In his consulting hours
the patients came into his room and stood in a row. One after another stepped for-
ward and described his complaint: he had back-ache or pains in his stomach or had
tired legs, and so on. The doctor then examined him and, after satisfying himself as
to what was the matter, called out the diagnosis, which was the same in every case.
He translated the word to me; it meant approximately 'bewitched'. I asked in
astonishment whether the peasants made no objection to his verdict being the same
with every patient. 'Oh, no!' he replied, 'they are very pleased with it: it is what
they expected. Each of them, as he went back to his place in the row, showed the
others by looks and gestures that I was a fellow who understood things.'

(Freud, 1933, p. 140)

This again shows us that, for the patient, a diagnosis, thanks to its links to suggestion, can very well function as a kind of currency, allowing him to leave the consultation "very pleased" - not to mention the physician, for whom it can represent a patent on knowledge, as well as a guarantee. In this way, diagnosis serves as a kind of magical formula, giving the doctor a position of influence previously only occupied by the magician.

Yet beyond the subjective implications acquired by the curious "object" of diagnosis in the discursive exchange between the doctor and the patient, the real goal of Freud's "anecdote" is to show the weakness of diagnostic analysis in Adler's "individual psychology" (reducing its conclusions to "commonplace truths", to "ancient pieces of wisdom [which] keep on cropping up") and to remind Freud's audience of the significance of nosography 
for his own field. The lack of diagnostic distinction may result in bringing together cases that in reality have nothing in common with each other and, as Freud somewhat jokingly adds, would allow us to use the same theoretical referents to explain, simultaneously and identically, a host of entirely distinct conditions, such as "a homosexual or a necrophilic, a hysteric suffering from anxiety, an obsessional neurotic cut off from society, or a raving lunatic" (Freud, 1933, p. 140).

The anecdote therefore highlights a need for "discernment" permanently present in Freud's clinical practice. Crucially, this requirement also intersects with an ideal of rationality Freud valued deeply because it structured the entire field whose conditions of intelligibility he established. This was most eloquently and straightforwardly summed up in his well-known letter to Lou Andréas-Salomé dated 30 July 1915: "What interests me is the separation and breaking up into its component parts what would otherwise flow together in a primeval pulp" (Freud, 1970, p. 309, our emphasis). That this constitutive ideal of the Freudian logic results in assuming a particular attitude in clinical practice - in Freud's words the "primeval pulp" of the clinic, where different clinical pictures appear "intermixed" - and therefore concerns diagnosis is attested to by another of his formulations, which is somewhat similar but refers to the problem of nosology directly. We find it when Freud, on his return to Vienna, praises Charcot's visionary talent:

In his mind's eye the apparent chaos presented by the continual repetition of the same symptoms then gave way to order: the new nosological pictures emerged, characterized by the constant combination of certain groups of symptoms. The complete and extreme cases, the 'types', could be brought into prominence with the help of a certain sort of schematic planning, and, with these types as a point of departure, the eye could travel over the long series of ill-defined cases - the 'formes frustes' - which, branching off from one or other characteristic feature of the type, melt away into indistinctness.

(Freud, 1893, p. 11, our emphasis)

This shows that the problem of "diagnostic discernment" left a lasting mark on the founder of psychoanalysis: the "schematic planning" of the diagnostic "types" leads to the "emergence" of "new nosological pictures", introducing order into the previous "chaos" in the field of neuroses. It takes us from a state of diagnostic confusion, where the clinician's "eye" "becomes lost in indistinctness", to being able to read a whole range of clinical forms, no matter how ill-defined, indistinct or bizarre, by comparing them with a clearly defined type. From the very beginning, Freud therefore calls our attention to the usefulness of diagnostic rationality, which has nothing to do with reducing or simplifying individual cases.

On the contrary, it is a question of finding the nodal point between the undefined material of a case and the over-defined nature of a type - in other words to articulate the connection between the singularity of a concrete individual and the generality of an abstract nosological picture. The diagnostic question always revolves around the observation of singularity and its subsequent reduction to the regularity of form; each time, we are 
looking for an identity in a variety of cases, which might be considered similar to a certain degree. The problem is, of course, precisely this "degree": to what extent can any clinical case be universalized; to what extent do the "ill-defined forms" remain linked to a definite type by a "characteristic sign"; to what extent must any case be seen as absolutely singular? To what extent does naming let us identify the logic (a pathology) one case shares with others - a logic necessarily known in advance (and later recognized). And, vice versa, to what extent does this identification leave aside some traits that are absolutely unique to each case? To understand the effects of this double-edged question means realizing that the diagnostic process always comes down to identification in the etymological sense, i.e. to making one case identical to another by relating it to a preestablished form. This reduction requires that we initially neglect the idiosyncratic elements that escape every identification, and only later, as a second step, pay attention to what gives a case its singular colouring, its unprecedented character.

This is very much how Freud understood Charcot's work. In the introduction to his translation of the Tuesday Lectures, he points out precisely this logic of identification-discrimination in the process of comparing a new case to what is already known:

[Charcot] questions the patient, examines one symptom or another, and in that way determines the diagnosis of the case and restricts it or confirms it by further examination. We observe that he has compared the case before him with a collection of clinical pictures derived from his experience and stored in his memory, and has identified the appearance of the present case with one of these pictures. This too is indeed the way in which we all arrive at a diagnosis beside a sick-bed [...] This is followed by differential diagnostic comments, and the lecturer endeavours to make clear the grounds on which his identification was based: grounds which, as we know, some good diagnosticians are unable to formulate, though they have their judgement determined by them. The further discussion relates to the clinical peculiarity of the case. [...] While the description of clinical pictures is the subject-matter of nosography, the task of clinical medicine is to follow out the individual form taken by cases $[\ldots]$

(Freud, 1892-94, p. 133)

Here, Freud presents the diagnostic procedure as essentially a two-step process, where we first include a case in one of the known nosographic types, thus positioning it in a system of classification, only to then identify its "individual form", which resists this identification. The second step is crucial because it prevents us from reifying individual phenomena, in other words from obscuring the subjective effects of the disease, which remain vital to the understanding of any given case.

\section{Diagnosis: Between nosographic ambition and clinical practice}

Diagnosis therefore lies in the tension between what is most common and what is most singular, between typicality and specificity. Revisiting this initial set of questions, which are intrinsic to the diagnostic procedure as such 
- i.e. what does the diagnostic act seek to identify, the typical or the singular - is not simply meant as a vaguely epistemological prologue on medicine in general. Quite the contrary: these problems concerned the founder of psychoanalysis deeply and they took on a very specific configuration in the Freudian field.

Indeed, looking at the function of the neurotic symptom as it is presented in its most theoretically developed form in the Introductory Lectures on Psycho-Analysis, we see that the very same division persists at the heart of the Freudian approach. There is a tension between, on the one hand, what is specific to each case, resulting in a symptomatology marked by "individual traits", which are directly linked with "historical truth", and, on the other hand, what the case shares with others, the "typical", i.e. so to speak, 'anonymous' symptoms, which "give us our bearings when we make our diagnosis". These latter symptoms are therefore very important, yet their value to the analyst seems to be lesser due to their resistance to "historical interpretation" - as Freud stated: "Individual distinctions disappear in them or at least shrink up to such an extent that it is difficult to bring them into connection with the patients' individual experience and to relate them to particular situations they have experienced" (Freud, 1916-17, p. 269). This shows us a radical tension between symptoms encoding a highly specific meaning, which is always unique and not even common to a given psychic organization, and "typical" symptoms, which we encounter regularly. The latter have a high predictive value for diagnosis but remain silent about the wide variety of individual truths.

This particular configuration of the individual and the universal in the Freudian field is no doubt the reason why psychoanalysts generally remain suspicious of diagnostic investigation; it also explains their resistance to relying on "typical symptoms" - which tell us nothing about subjective truth - and their concern with the deep idiosyncrasy of any given case. This attention to idiosyncrasy follows directly upon Freud's constant concern with the "individual form of the symptom" as the patient's mode of self-expression. Because for Freud, the more singular the text of the symptom, the higher its signifying value, among the main characteristics of psychoanalysis is its praise of singularity, its constant effort to uncover "enough individual traits to make what I might call a 'historical' interpretation possible" (Freud, 1916-17, p. 269). Of course this attitude is very common among psychoanalysts, but we must remember that case variation never discouraged Freud from trying to construct a series and that he refused to hesitate indefinitely between the absolute singularity of a case and the complex interplay of forces, limits and determinations, through which any isolated case largely exceeds the limits of the individual.

However, to explain this permanent tension within the Freudian corpus, we must start by looking at where Freud first comes across it: the lesson in fact comes from Charcot. The problem of the connection between subjective singularities and, let us say, universal notions of mental pathology is equally central to Charcot's teaching; it is this conception that guides all of Freud's first nosology, as well as his own understanding of it. 


\section{Charcot, the clinician and the nosographer}

Charcot's work is based on a specific concept of clinical approach which he calls, somewhat interchangeably, the 'nosological' or 'nosographic method': its aim is to identify, within the heterogeneity of individual cases and singular instances of the clinical material, a pathological type, which can supposedly be isolated as the complete form of a disease, a kind of central, perfect, stripped-down or canonical version of a whole series of symptomatic pictures.

Certainly in Charcot's view, the "type" can obviously only be described based on its clinical visibility, when facing the patient and temporarily disregarding the need for understanding in favour of the "value of this kind of seeing" (Freud, 1893, p. 11), which Freud says is the basis of "purely clinical work". But in his mind, the descriptive task of the nosographic researcher and that of the clinician dealing with a case are obviously very different, precisely because they occupy different positions in the dialectic of the singular and the universal. In his work, Charcot constantly reminds us of the epistemological gap, central to his method, between "nosography" and the "clinic", associating them with two different and mutually opposite rationalities. It is no coincidence that he should stress this question in one of the first lectures given at the Salpêtrière. "The task of the clinical observer differs from that of the nosographic researcher," he says, in that the first "cannot neglect exceptional and abnormal cases" and their complex clinical pictures (i.e. everything to do with the "atypical" nature of a case, which Freud recognizes as the work of individual factors), while the second "concerns himself chiefly with the abstract picture of diseases; hence, he purposefully neglects anomalies - deviations from the typical standard - or willingly relegates them to the background" (Charcot, 1881, p. 3). Through this gesture of abstraction, or "schematization", to use Freud's own word, the pathology begins to appear legible, resulting in a typology of neuroses, which will serve as the point of departure for Freud's own work.

What Charcot likes to call the "pathological morphology" therefore means, firstly, to select "material" and, secondly, to extract a model from it. In a posthumous article dedicated to Charcot, Janet describes this process remarkably well:

The notion of a pathological type plays such a significant role in all of Charcot's research that we must pause here for a moment. In order to study a disease, Charcot chooses from the different afflicted subjects one specific individual, whom he presents and describes in preference to all the others. [...] Why was this individual chosen? [...] Was his illness more serious than in the others? No, it often happens that Charcot considers some of the most disturbing symptoms presented by patients as purely coincidental, as an addition to a typical disease. Was it then because the patient's symptoms were more numerous and complete than those of others? The number of phenomena is not important because in many cases the additional symptoms are related to two different pathologies, which have come together in a single individual. Is he therefore choosing, as it would seem natural, the most common or frequent form assumed by the illness? This may be true for some types, but it is certainly not the general principle behind Charcot's thinking. Most of the patients coming to the 
consultations are considered exceptions, irregularities or complications: when we do see typical cases, they are treated as remarkable and retained as curiosities. [...] What logic therefore guides the choice of what Charcot calls a type of disease? The chosen individual presents neither the greatest number of symptoms nor those most frequently encountered, but instead the most clearly defined and the most intelligible. The type is an entire series of symptoms, which are clearly interdependent, which form a hierarchy and can be divided into well-defined groups and, crucially, whose nature and combinations distinguish them from the characteristics of other diseases.

(Janet, 1895, pp. 575-6)

We quote this passage at length because it shows the direction from which Charcot never deviated and which to him remained a focus point on the wider horizon of medical knowledge. This is restated in a lecture of 20 March 1888, one of those translated by Freud:

Studying types is the fundamental task of nosography. Duchenne de Boulogne practised it instinctively, as have many others before and after him: it is the requisite and the only effective way of extracting a specific pathological species from the chaos of imprecise notions.

(Charcot, 1888, pp. 278-9)

Freud was highly influenced by this methodological approach and it is precisely its originality that he designated, in his brief introduction to the translation of the Lectures, as the "main characteristic of the French method of clinical practice":

The clinical picture, the 'entité morbide', remains the basis of the whole study; but the clinical picture consists in a series of phenomena, a series which often branch off in a number of directions. The clinical assessment of the case lies in assigning it its place in this series. In the centre of the series lies the 'type', the consciously and intentionally schematized extreme form of the clinical picture; or several such types can be set up, which are connected by transitional forms.

(Freud, 1892-94, p. 134)

The theme of the "typical" in fact runs through the entire body of Freud's work. The difficulties associated with this concept, some of which we have already discussed, must be understood in this context. This is key because, as we know, when Freud's theory has reached its mature state, the more closely the idiosyncratic characteristics of a symptom ties it to its historical determination, the more meaningful it becomes. The purely singular "symptom's formal envelope" which is, precisely, located within the series as "atypical", is therefore responsible for encrypting and channelling its unconscious meaning. In other words, it is precisely in this strangeness of a "detail", in the atypical bizarreness of the symptom, that we see the mark of the subjectivity. As Freud stated: "On this similar background, however, different patients nevertheless display their individual requirements - whims, one is inclined to say - which in some cases contradict one another directly" (Freud, 1916-17, p. 269). 
Unless we understand this, we risk missing an essential fact: the profound efficacy of Charcot's method does not lie in its ability to construct a schema of a "type", but in its clinical use, in the "second nosographic operation" which consists in applying the "nosographic type" to clinical practice:

Once the type is established, the second nosographic operation begins: we must learn to dissect the type and analyze its parts. In other words, we must learn how to recognize the imperfect, indistinct or rudimentary cases. The disease created by this method then appears in a new light. The field is expanded: the illness becomes much more important in clinical practice and for the patient's benefit, the physician makes more effort to recognize the disease, even when it is still in its earliest stages.

(Charcot, 1888, p. 279)

The usefulness of the type therefore becomes manifest in its fragmented, truncated form. The validity of a model, created from a series of imperfect and incomplete forms, which are always concretely original, is confirmed by its subsequent elasticity, its ability to designate and determine other forms. The isolated, carefully chosen type, which is then "retained as a curiosity" (as Janet puts it), provides clinical observation with a tool it can use to sift through and identify a variety of truncated and atypical clinical forms.

Freud perfectly understood the role of this "second operation":

It is certainly true that the 'type', the complete and characteristic portrayal of the clinical picture, can be met with; but the cases that are actually observed diverge as a rule from the type: one or another of the picture's traits is obliterated; they can be arranged in one or more series departing from the type and end at last in quite indeterminate, rudimentary forms [formes frustes], in which only the expert can still recognize derivatives of the type.

(Freud, 1892-94, p. 133)

In his eponymous essay, he relates the strong impression made on him by Charcot to this complete series of steps:

In his mind's eye the apparent chaos presented by the continual repetition of the same symptoms then gave way to order: the new nosological pictures emerged, characterized by the constant combination of certain groups of symptoms. The complete and extreme cases, the 'types', could be brought into prominence with the help of a certain sort of schematic planning, and, with these types as a point of departure, the eye could travel over the long series of ill-defined cases - the "formes frustes' - which, branching off from one or other characteristic feature of the type, melt away into indistinctness. He called this kind of intellectual work, in which he had no equal, 'practising nosography', and he took pride in it.

(Freud, 1893, p. 11)

\section{Actual neuroses and the 'clinical type'}

The influence Charcot's "method of clinical types" had on Freud is most evident in the texts delineating what the latter calls the field of "actual 
neuroses", whose aetiology does not derive from "psychological mechanisms". These neuroses are first identified as "complexes of symptoms", most importantly in relation to Freud's longest-defended nosographic innovation, the anxiety neurosis: "What I call 'anxiety neurosis' may be observed in a completely developed form or in a rudimentary one, in isolation or combined with other neuroses. It is of course the cases which are in some degree complete and at the same time isolated which give particular support to the impression that anxiety neurosis is a clinical entity" (Freud, 1894a, p. 91, our emphasis).

We can notice that, looking at a singular case, Freud proceeds exactly as Charcot would have done in trying to identify the "typical hysterical attack":

\begin{abstract}
Now it is an interesting fact, and an important one from a diagnostic point of view, that the proportion in which these elements are mixed in an anxiety attack varies to a remarkable degree, and that almost every accompanying symptom alone can constitute the attack just as well as can the anxiety itself. There are consequently rudimentary anxiety attacks and equivalents of anxiety attacks, all probably having the same significance, which exhibit a great wealth of forms that has as yet been little appreciated. A closer study of these larval anxiety-states and their diagnostic differentiation from other attacks should soon become a necessary task for neuropathologists.
\end{abstract}

(Freud, 1894a, p. 94, italics are original)

In other words, Freud follows the dull and narrow yet productive path of differential diagnosis first followed by Charcot, but what he identifies as a ground for diagnosis is not a radically new set of symptoms but their mutual connections, the fact that they can function as mutually equivalent, that they can appear as larval states, as essentially identical but ill-defined forms of the "disease process". It is the idea that even a shadow of a symptom can retain all its "signifying value".

All of this may seem far from Freud as we know him, especially because the "actual neuroses" represent an epistemic zone we tend to see as somewhat alien to the rest of his theory. It is, however, crucial: the relationship between a symptom and a "type" is precisely what makes it possible for an atypical manifestation to function as a symptom, to draw our attention and emerge as a "singular fact"2 which should be questioned. The traces of this method are especially visible in all of Freud's clinical texts dealing with "the general picture". A good example is the incipit of his essay on melancholia, ${ }^{3}$ where the secret enjoyment inherent to the melancholic discourse is again

\footnotetext{
${ }^{2}$ We could relate this to what Ernest Jones tells us about "Freud's characteristic way of working": "His great strength [...] was the quite extraordinary respect he had for the singular fact. [...] The single fact would fascinate him, and he could not dismiss it from his mind until he had found some explanation of it" (Jones, 1956, pp. 106-7).

3“"Melancholia, whose definition fluctuates even in descriptive psychiatry, takes on various clinical forms the grouping together of which into a single unity does not seem to be established with certainty [...] we shall console ourselves by reflecting that, with the means of investigation at our disposal today, we could hardly discover anything that was not typical, if not of a whole class of disorders, at least of a small group of them" (Freud, 1917, p. 242).
} 
found in a trait (Freud, 1917, p. 246), which then allows Freud to reconstruct the entire pathological "process".

\section{Diagnosis in Freud's Neurosenlehre}

Although in Freud's early work the influence of Charcot's method becomes most manifest in the differentiation of the actual neuroses, it is also employed in the context of the psychoneuroses (in his 'pre-analytical' period Freud considers the field he is trying to map out as essentially homogeneous). This is expressed in the clinical pairings he frequently brings to the reader's attention and in their aetiological complementarity, which arranges them into series. It also allows him to construct a series of structural oppositions (current/infantile, somatic/psychic, genital sexuality/psychosexuality, etc.).

Here we may turn to Freud's private correspondence with Flies, which records the key stages in the genealogy of his Neurosenlehre. For example in Draft $K$ the still largely unclear field of the psychoneuroses is again organized around "four types and numerous forms of the neuroses of defence" (Freud, 1896b, p. 220). Hysteria, obsessional neurosis, paranoia and acute hallucinatory amentia become clinical types; however, in the framework of the psychoneuroses, which depend on a specifically psychosexual aetiology, the "type" is given a new meaning, a new and properly Freudian basis. It no longer concerns just symptoms, but specifies the relationship of each clinical picture to its characteristic mode of defence. From the shadows cast on his early work by Charcot, we now see emerging Freud's own true face.

This radical turn towards "sexual aetiology" in fact corresponds to a moment when Freud feels obliged to "repay a debt of gratitude, but also [to indicate] the point at which [his] own work branches off from the master's" (Freud, 1906, p. 4). Leaving this mutation momentarily aside (since it concerns the parts of Freud's work probably best known to our readers) and pursuing the question of "repaying a debt of gratitude" a little further, we come to the last element Freud borrows from Charcot's nosological method. It concerns the nosographic position of the so-called "mixed forms" - an expression which diagnostic assessment might consider as inherently polemical.

As Freud very well understood, "the work of nosography" is what led Charcot to "pick out [the classical clinical types] from the chaos of previous "neuroticism", and then to introduce them "into the field of clinical neuropathology, where [they] now hold a legitimate place" (Charcot, 1891, p. vii).

We must remember that Charcot's contribution to knowledge was not limited to the study of hysteria. And although historiography has often given hysteria an overly central place, we should, at least for now, try to free ourselves from its fascination - largely owed to its "dazzling" clinical aspects (Freud, 1916-1917, p. 421) - and realize that what is tacitly transmitted from Charcot to Freud actually far exceeds the study of this single form. For example, although this rarely receives attention, Charcot's work also produced a rigorous definition of neurasthenia, which, too, served as a departure point for Freud's research. 
The history of neurasthenia - which in France still remains connected with the name of Charcot as its first supporter and "godfather" relevant to our discussion because it illustrates remarkably well how Freud not only followed in Charcot's steps but carried his ideas much further. When it was imported into France, neurasthenia was still poorly defined:

The most important task was to purify, if we may use this expression, the nosological picture of neurasthenia, ridding it of certain foreign elements which had been wrongly introduced by a number of authors, including Beard himself [here we see Charcot's operation of abstraction, which results in the formation of a type]. Agoraphobia, mysophobia, onomatomania, arythmomania and other episodic syndromes of vesania of doubt had to be completely eliminated from its framework.

(Charcot, 1891, p. XI)

We now realize that by separating neurasthenia from obsessional neurosis (vesania of doubt), Freud strictly followed the differential path first beaten by Charcot; however, reading further, we also understand what was implicitly transmitted through this theoretical elaboration. Charcot argues that the symptoms in question are in fact "stigmata of hereditary degeneracy, which, when they are present in neurasthenia, which is not very rare, point to a complication in the patient [...] these are not symptoms emanating from the primary disease" (Charcot and Levillain, 1891, p. xi). The "nosological picture" of a case appears as impure only insofar as it presents a combination - "which is not very rare" - of symptoms belonging to different fields, in other words, a complication of two distinct clinical types.

Because this statement ultimately turns towards the concept of degeneracy, this transmission might easily be lost on us, or appear as recessive, although Charcot's argument briefly seems to show clearly the direction Freud will follow. Yet what Charcot is showing us here, as if in passing, is a tension structuring all of his own nosology, but also the earliest nosology of Freud. Its central lines could be formulated as follows: firstly, "despite subjective variation, the pathological type remains unchanged, except for a few secondary modifications" (Charcot and Levillain, 1891, p. xi); secondly, although the type may undergo "modifications," all "ill-defined forms" contain an indelible trace of the primitive type and therefore demonstrate its validity and its fixity. Thirdly - and most importantly - in clinical practice we only encounter these forms in a mixed state, where they combine with other pathological forms, with other autonomous pathological types. In fine, the initially isolated pure "type" enables us to dissect and analyse mixed or combined forms combined in a single clinical picture:

I would again like to stress the key nosological fact that even and perhaps especially in mental pathologies the pathological species or types represent, in the combination of their clinical characteristics, a true fixity, a real originality which nearly always allows us to recognize them or to separate them analytically, even when several of these

\footnotetext{
4"The work of Charcot, whose clinical method is equally rigorous, largely contributed to the clarification of the characteristics of this new neurosis and to its defence against an invasion of cumbersome and obscure descriptions. If Beard could be called the father of neurasthenia, in France Charcot was its godfather" (Levillain, 1891, p. 13, our translation).
} 
species coexist in the same individual, where they may result in a wide variety of complexes. The argument I would like to defend in such matters is [...] that in reality these nosological complexes do not represent hybrid forms, variable and unstable results of an immixture, of an intimate fusion. Instead, they are the results of an association, of a juxtaposition where each component remains autonomous.

(Charcot, 1889, p. 151)

In his passion for differential diagnosis, Charcot therefore orients his clinical work towards analysis in the strictest sense of the word, that is, the breaking-down of a clinical picture along its constitutive lines, in order to isolate its autonomous components - the fixed and distinct nosological complexes which have become closely intertwined. Following Charcot's text, a reader familiar with Freud's work may be struck by a sort of paramnesia, a feeling of déjà $l u$ ['already read']: as we know, Freud later applied the same process, and with equal rigour, to the construction of his own nosology of the neuroses, enabling him to separate each of the components from their complex interlinking within the clinical picture and to "discover an intermixture of several specific aetiologies" (Freud, 1894a, p. 112).

\section{Mixed neuroses and etiological analysis}

In the early years of his neurological practice, Freud was in fact regularly forced to describe the clinical pictures of his cases as "mixed neurosis" (Freud, 1894b, p. 59), thus requiring a method to respond to the task of dissecting complex structures and "separating by means of analysis" their constitutive elements, which are initially present in a "clinical intermixture" (Freud, 1894a, p. 111) of different registers.

We have already discussed the important role which the "nosographic lesson' (Villa, 2007) plays in the formulation of this key task of clinical analysis, during Freud's first mapping out of the field of the neuroses. Yet, if we would like to relate this lesson to Charcot, it is mainly because the original lesson of the master of the Salpêtrière greatly informed and subsequently clarified the method in Freud's own work. Indeed, reading Charcot we understand that Freud's 'mixed neurosis' could never designate a 'clinical category' sui generis. This fact is of course common enough and largely admitted by clinical psychoanalysis. However, although Freud often encounters clinical pictures combining typical symptoms of different neuroses (often including elements from the most clearly distinguished registers, such as the psychoneuroses and the actual neuroses), and although he may sometimes be tempted to identify them as a "new type", 5 the fact remains

\footnotetext{
5"[The psychoneuroses] make their appearance as a result of two kinds of determinants, either independently or in the train of the 'actual neuroses' (neurasthenia and anxiety neurosis). In the latter case we are dealing with a new type of neurosis - incidentally, a very frequent one - a mixed neurosis." However, we must read on to realize that these mixed neuroses are not given any nosological endorsement: "The aetiology of the 'actual neuroses' has become an auxiliary aetiology of the psychoneuroses. A clinical picture arises in which, let us say, anxiety neurosis predominates but which also contains traits of genuine neurasthenia, hysteria and obsessional neurosis. When confronted with a mixture of this kind, we shall nevertheless not be wise to give up separating out the clinical pictures proper to each neurotic illness; for after all it is not difficult to explain the case to oneself in the following manner, etc." (Freud, 1898, p. 278).
} 
that they cannot be understood as "hybrid forms, the variable and unstable results of an immixture, of an intimate fusion. Instead, they are the results of an association, of a juxtaposition where each component remains autonomous", as Charcot (1889, p. 151) himself put it. Thus, Charcot's formulation clearly articulates a thought which Freud's work further develops: the clinical picture is composed of elements which retain their unity regardless of the 'immixture' observed by the clinician.

In conclusion, I may point out that combinations of a phobia and an obsession proper may co-exist, and that indeed this is a very frequent occurrence. We may find that a phobia had developed at the beginning of the disease as a symptom of anxiety neurosis. The idea which constitutes the phobia and which is associated with the state of fear may be replaced by another idea or rather by the protective procedure that seemed to relieve the fear. Case 71 (obsessive speculating) presents a neat example of this group: a phobia along with a true substitutive obsession.

(Freud, 1894c, pp. 80-1, original emphasis)

For what regards the question of mixed neuroses, this remark, in addition to being one of Freud's texts written in French and hence addressed to Charcot's students, is highly illuminating, if taken literally: an autonomous pathological mechanism is combined with another modality, which is compatible yet heterogeneous to it. Instead of an 'immixture' we should therefore be speaking of 'superimposition' (or even leaning on) because each of the constituting forms that have become condensed in a single clinical picture preserves its own logical coherence. As Charcot puts it: "They do not mix or merge together; they do not produce hybrids" (Charcot and Levillain, 1891, p. xii).

And this is precisely what Freud takes from Charcot when creating his own nosography during the period of 1893-1896, based on his great concern with differentiating between the neuroses and allowing him to separate their causal mechanism ever more precisely. The transmitted 'lesson' also results in a particular diagnostic position, whose influence on psychoanalytic nosology has so far received little attention. Yet it is explicitly formulated already in the Studies on Hysteria: a potiori fit denominatio (Breuer and Freud, 1895 , p. 258), that is, the name comes from the most distinctive, the most typical of the traits the case presents. This becomes the axiom of Freud's nosology. And here we come to the most interesting fact: we now see that in Freud's work, clinical observation - that neuroses are rarely present in a pure state but instead as a symptomatic "immixture" - exists alongside a constantly reiterated nosographic imperative - that the clinical prevalence of "mixed neuroses" should not lead us to "oppose any dividing lines in the chaotic world of neurotic phenomena, any segregation of clinical entities or individual diseases" (Freud, 1916-17, p. 389).

This is a diagnostic imperative Freud never betrays: "It is quite true that in our daily practice we very often see neurasthenic and hysterical symptoms mixed together, however this in no way prevents us from separating the two conditions conceptually, i.e. from a diagnostic perspective" (Freud, 1987, pp. 342-3). Today, his warning still rings true for every analyst, 
insofar as it reminds us that Freud was able to mark out the field of the unconscious, i.e. the field of psychoanalysis, only by separating meaning from what cannot be analysed, and that the distinction between the formations of the unconscious and symptoms that are not symbolically encoded is, again, a matter of diagnosis.

For Freud, this position, between staying true to the complexity of each clinical picture, which may prevent us from distinguishing its elements, and the nosological tendency to reduce complexity to simply an aggregate of basic elements, is not only profoundly consistent with the notion of "analysis" $"$ as the epistemological pivot of his field, but it also distinguishes the rationality of its clinical practice from the larger field of clinical medicine:

\begin{abstract}
Doctors usually take very little interest in a good many of the questions which are discussed among neuropathologists in connection with the neuroses: whether, for instance, one is justified in making a strict differentiation between hysteria and neurasthenia, whether one may distinguish hystero-neuras-thenia alongside of them, whether obsessions should be classed with neurasthenia or recognized as a separate neurosis, and so on. And, indeed, such distinctions may well be a matter of indifference to a practitioner, so long as no further consequences follow from the decisions arrived at - no deeper insight and no pointers for therapeutic treatment - and so long as the patient will in every instance be sent off to a hydropathic establishment, and be told that there is nothing the matter with him. But it will be a different thing if our point of view about the causative relations between sexuality and the neuroses is adopted. Fresh interest is then aroused in the symptomatology of the different neurotic cases, and it becomes of practical importance that one should be able correctly to break down the complicated picture into its components and correctly to name them. For the morphology of the neuroses can with little difficulty be translated into aetiology and acknowledgement of the latter leads on quite naturally to new indications for methods of cure.
\end{abstract}

(Freud, 1898, pp. 265-6)

It is obvious that Freud's discovery of the "aetiology of the neuroses" runs parallel to their nosographic breaking-down: he speaks of "strict differentiation", of "distinction" and "division", of "correct naming". However, we must also understand the logic behind this classification: the symptomatology of the "complicated picture" arouses "fresh interest" precisely because it corresponds to a certain idea "about the causative relations between sexuality and the neuroses". We can only gain "deeper insight" into a case based on the visibility of its clinical manifestations, on a clinical level. Here, Freud makes a much more direct connection between symptomatology and aetiology than Charcot, when he says that the "morphology of the neuroses" - an expression borrowed spontaneously from the great Master - grasped from the organization of its "components", can "with little difficulty be translated into aetiology". Let us also remember that

\footnotetext{
6"Why 'analysis' - which means breaking up or separating out, and suggests an analogy with the work carried out by chemists on substances which they find in nature and bring into their laboratories? Because in an important respect there really is an analogy between the two. The patient's symptoms and pathological manifestations, like all his mental activities, are of a highly composite kind" (Freud, 1919, pp. 158-9).
} 
translation is one of Freud's most original ideas: interpretation, which reveals both the meaning of a symptom and its aetiological explanation, works by "re-translating [the symptom] into sexual terms" (Freud, 1894b, p. 56).

Hence we see the decisive role of diagnosis in Freud's discovery: in early Freud, diagnostic designation is always also an aetiological specification, due to its connection with the mechanisms of the unconscious.

In the framework of the seduction theory, this precise matching of each component of the symptomatology to a specific etiological register is particularly distinct, thus showing us its decisive value. Its visibility is amplified by Freud's hypothesis of the double aetiology of obsessional neurosis, which always includes a hysterical substratum, doubling the neurotic's guilt by positing a passive experience of seduction prior to its active experience. ${ }^{7} \mathrm{We}$ must of course understand the argument in the context of Freud's "error", 8 but we should take his position seriously for what it is, namely an expression of an epistemological requirement: the "formation of a symptom" is always linked to a "specific cause" which acts as a "determinant". This is by no means a circumstantial claim but a fundamental issue and we find traces of it even in the most developed arguments of the Freudian psychopathology - for proof we refer the reader to Inhibitions, Symptoms, and Anxiety.

\section{From symptom to neurosis: Freud's mineralogy}

Moving along the path that leads Freud from the clinical 'museum' of the Salpêtrière to the unconscious fantasy, we see the figure of Charcot and the source of inspiration that his work initially represents for Freud gradually fading away. However, this source remains connected to and fuelling an ideal from which Freud subsequently never departs and which has become constitutive of his own rationality.

\footnotetext{
7" Sexual experiences of early childhood have the same significance in the aetiology of obsessional neurosis as they have in that of hysteria. Here, however, it is no longer a question of sexual passivity, but of acts of aggression carried out with pleasure and of pleasurable participation in sexual acts - that is to say, of sexual activity. This difference in the aetiological circumstances is bound up with the fact that obsessional neurosis shows a visible preference for the male sex. In all my cases of obsessional neurosis, moreover, I have found a substratum of hysterical symptoms which could be traced back to a scene of sexual passivity that preceded the pleasurable action. I suspect that this coincidence is no fortuitous one, and that precocious sexual aggressivity always implies a previous experience of being seduced" (Freud, 1896c, pp. 167-8).

8“This section is dominated by an error which I have since repeatedly acknowledged and corrected. At that time I was not yet able to distinguish between my patients' phantasies about their childhood years and their real recollections" (Freud, 1896c, p. 167).

9 "Obsessional neurosis originates, no doubt, in the same situation as hysteria, namely, the necessity offending off the libidinal demands of the Oedipus complex. Indeed, every obsessional neurosis seems to have a substratum of hysterical symptoms that have been formed at a very early stage. But it is subsequently shaped along quite different lines owing to a constitutional factor. The genital organization of the libido turns out to be feeble and insufficiently resistant, so that when the ego begins its defensive efforts the first thing it succeeds in doing is to throw back the genital organization (of the phallic phase), in whole or in part, to the earlier sadistic anal level. This fact of regression is decisive for all that follows" (Freud, 1926, p. 112). It is obviously not a coincidence that the idea of the hysterical substratum of obsessional neurosis is put forth in a text where we also see the emergence, after 30 odd years, of the generic notion of 'defence', and thus of the idea of an array of defensive strategies.
} 
Its importance must be recognized because Charcot's logic of separation continues to provide strong orientation for Freud's nosography, leading him, including in his much later texts, to dissect the "mixed states", whose existence he always maintains. At the same time, it allows him to formalize these states in the terms of his epistemic model:

\begin{abstract}
All the names are in use, it is true, but their content is indefinite and fluctuating. There are even doctors who oppose any dividing lines in the chaotic world of neurotic phenomena, any segregation of clinical entities or individual diseases, and who do not even recognize the distinction between the 'actual' neuroses and the psychoneuroses. I think they are going too far and have not chosen the path which leads to progress. The forms of neurosis which I have mentioned occur occasionally in their pure form; more often, however, they are intermixed with each other and with a psychoneurotic disorder. This need not lead us to abandon the distinction between them. Consider the difference between the study of minerals and of rocks in mineralogy. The minerals are described as individuals, no doubt on the basis of the fact that they often occur as crystals, sharply separated from their environment. Rocks consist of aggregations of minerals, which, we may be sure, have not come together by chance but as a result of what determined their origin. In the theory of the neuroses we still know too little of the course of their development to produce anything resembling petrology. But we are certainly doing the right thing if we start by isolating from the mass the individual clinical entities which we recognize and which are comparable to the minerals.
\end{abstract}

(Freud, 1916-17, p. 389)

The mineralogical metaphor is striking because it precisely illustrates the structural solidity acquired in Freud's view by each of the components observed in the clinical picture. Each component must be seen as a "clinical individuality", in the exact same way that the crystal-like structure of a mineral separates it from the surrounding "rock", where such minerals are merely "aggregated" without ever merging together. If we take this metaphor further, we could say that in the psychoanalytic mineralogy we never encounter anatexis.

We come across the same metaphor in the New Introductory Lectures; the crucial difference is that it is now used to describe the neurotic personality itself. ${ }^{10}$ Here, we get a glimpse of a movement fundamental to the entire Freudian psychopathology, which deserves separate attention because it gradually reveals the object of psychoanalytic diagnosis. Following the trajectory of Freud's formalization, we see a terminological and conceptual shift from the nosological entity to the organization of the personality of the symptom-bearing subject (from hysteria to the hysteric, from obsessional neurosis to the obsessional, etc.). Its first phase schematically corresponds to Freud's clinical attention to "the formations of the unconscious" and,

\footnotetext{
10 "[...] we are familiar with the notion that pathology, by making things larger and coarser, can draw our attention to normal conditions which would otherwise have escaped us. Where it points to a breach or a rent, there may normally be an articulation present. If we throw a crystal to the floor, it breaks; but not into haphazard pieces. It comes apart along its lines of cleavage into fragments whose boundaries, though they were invisible, were predetermined by the crystal's structure. Mental patients are split and broken structures of this same kind" (Freud, 1933, pp. 57-8).
} 
from the perspective of metapsychology, to the first topography, whose functioning these formations illustrate; its second phase follows upon his focus on subjectivity and is essentially the result of his "dissection of personality" as formalized in the second topography. Even despite this decisive re-centring of Freud's work on the underlying personality and the subjectivity of the symptom, insofar as he continues to see the symptom as an idiosyncratic formation, the Freudian case loses its privilege of absolute singularity. We now understand why: its function is in fact to demonstrate the existence of a "law, order and connection" at work in the sphere of the individual, so that "the most heterogeneous forms of mental disorder are revealed as the results of processes which are at bottom identical" (Freud, 1913, p. 173).

The mineralogical metaphor is a remarkable illustration of the rationality Freud employs in dissecting each "mixed picture" and of the extent to which this rationality remains indebted to Charcot's method, as its final stage and, in some sense, its ultimate crystallization.

\section{Conclusion: Diagnosis and the witch trial}

After discussing the continuities between Charcot's and Freud's work, we still have now to examine their dissonances. As soon as Freud takes into account the effects of the unconscious, his project can no longer be considered without a reference to its specific "method of treatment", thus radically transforming the "diagnostic concern", which played such an important role in Charcot's research.

To outline the key points of this mutation, as a starting point for a future article, let us simply say that the problem is that in psychoanalysis, the task of the clinician is no longer to see. "In medical training you are accustomed to see things. [...] In psycho-analysis, alas, everything is different. Nothing takes place in a psycho-analytic treatment but an interchange of words between the patient and the analyst" (Freud, 1915-16, pp. 15-16).

The above remark, which Freud decides to make at the beginning of his first Introductory Lecture, in fact poses, in no uncertain terms, the question of the object of diagnostic recognition, both in relation to what diagnosis allows us to identify and what it relies on, now that the essential referent of psychoanalysis no longer belongs to the register of the visible, but to the field of speech.

This is the kind of tension we must think about. As a physician facing his patient and watched by his eager audience, or standing over a body spread out on a dissection table, Charcot would not think twice about where to look for his object, but "in psycho-analysis, alas, everything is different". Here again we must take Freud literally: asked where we should look for the unconscious, the only answer he is able to give is his personal experience of analysis and of transference. His reaction in a sense resembles Oedipus' answer to the riddle of the Sphinx - nothing radical and unprecedented, no ingenious demonstration, nor cutting-edge knowledge, but an act, asking us to consider ourselves as the secret solution, as the only valid answer, given that the discovery of the object of psychoanalysis - the 
unconscious - requires that, in a sense, we ourselves shed light on our relationship to the blind spots of thought.

This reintroduces the question of "diagnostic discernment" into the Freudian discourse, where "discernment" no longer concerns a simple and objective description of a clinical picture from an outside position, but a need to also distinguish the effects of unconscious subjectivity and their relationship to historicity. It is therefore not surprising that at this crucial moment, when psychoanalysis is made distinct from medicine, Freud not only reintroduces the field of visible reality, but also the question of history and of the truth of what no longer is (Freud, 1915-16, pp. 17-18). Diagnostic discernment therefore requires us not only to "face the symptom" and deal with each case in a "detailed fashion" (Freud, 1915-16, p. 268) but also to look for the obscure subjectivity that exerts its effects from within, i.e. the unconscious.

The crucial vector of this research in psychoanalysis is of course transference, which gives the Freudian method its originality, by joining the question of diagnostics and thus of historical investigation to therapeutic action: "In hysteria, the auxiliary diagnostic tools, which lose their purpose once a pathology is discovered, become the means of therapy. By trying to find a trace of the repressed idea, the physician helps the patient lift the repression" (Freud, 1987, p. 338). This additional twist applied to medical rationality, this special kind of 'dignity' of analysis, is, unsurprisingly, also evoked in Freud's Recommendations to physicians: "One of the claims of psycho-analysis to distinction is, no doubt, that in its execution research and treatment coincide" (Freud, 1912, p. 113). This is so because research necessarily relies on the basis of psychoanalytic treatment, i.e. the fact of transference.

To take transference into account nevertheless implies a great number of changes into traditional diagnostics. As we know, in Freud's final formulation of the problem, the specificities in transference will be the major criterion that determines the diagnosis:

Our diagnoses are very often made only after the event. They resemble the Scottish King's test for identifying witches that I read about in Victor Hugo. This king declared that he was in possession of an infallible method of recognizing a witch. He had the women stewed in a cauldron of boiling water and then tasted the broth. Afterwards he was able to say: 'That was a witch', or 'No, that was not one'. It is the same with us, except that we are the sufferers. We cannot judge the patient who comes for treatment (or, in the same way, the candidate who comes for training) till we have studied him analytically for a few weeks or months.

(Freud, 1933, p. 154)

A critical issue is at stake here: being thrown into the "transferential cauldron" remains the only proof of a diagnosis worthy of the metapsychological "witch". Freud's words show us a focal point that must remain on the horizon of any research dealing with the function of diagnosis in psychoanalysis. They show that psychoanalysis is not just one psychopathology among others because it is based on a transferential reality that it is itself 
uniquely capable of assessing. In this sense, it is said that clinical psychoanalysis is a "clinic under transference.. Although it is not incorrect, the formulation fails to emphasize a crucial point, which, when speaking of Freud's contribution to psychopathology, should be made explicit. It is the fact that psychoanalysis is not just a clinic under transference, but a psychopathology of transference. This is why in the Freudian heuristic and beyond what Freud himself was able to understand, his method of treatment could function as a diagnostic tool from the very beginning, even before he was able identify the issues at stake in it. ${ }^{11}$

This of course brings us to the concept of 'transference neurosis' as a kind of third comparison between clinical neurosis and infantile neurosis, and to what it can tell us about the diagnostic procedure in psychoanalysis. If the idea is that by encouraging the symptom in the patient's relationship to the analyst we transform the structure of the neurosis, this must mean that the passive presence of the 'sign' is no longer sufficient: it only acquires its value by being addressed by one subject to another. The unconscious motivation of the sign shows us that on the path leading from Charcot to Freud, the diagnostic 'reality' has indeed undergone a profound change.

\section{Translations of summary}

Freud bei Charcot. Freuds Entdeckung und die Frage der Diagnose. Obwohl immer wieder auf den prägenden Einfluss verwiesen wird, den Charcot auf Freud ausübte, und Freuds Reise nach Paris und seine Studien bei Charcot als wegweisend für seine Umorientierung von der neurologischen zur psychopathologischen Arbeit unumstritten sind, wird ein entscheidender Fakt der Freudschen Heuristik bis heute weitgehend unterschätzt: dass nämlich Freuds psychopathologischer Durchbruch, der die Geburt der Psychoanalyse ermöglichte, nicht von seiner Beschäftigung mit Problemen der Diagnostik, einem zentralen und bisweilen sogar das oberste Organisationsprinzip seiner frühesten Schriften, zu trennen ist. Die Autoren stellen deshalb erneut die Frage der Diagnose, indem sie ihrer Entwicklung entlang dem von Charcot zu Freud führenden Pfad folgen. Sie zeigen, dass sich Freuds geschärfte Aufmerksamkeit für diagnostische Unterscheidungen strikt an der Richtung von Charcots „,nosologischer Methode” orientierte. Darüber hinaus versuchen sie, präzise zu klären, wie Charcots Ideen in Freuds eigenem Werk nachwirken; sie fragen, wie Freud mit Charcots Überlegungen arbeitete, um sein eigenes nosologisches System formulieren zu können. Die Autoren gehen das Schicksal nach, das die Charcotschen Lehren durch Freud erfuhren, und bestimmen auf der Grundlage der Bedeutsamkeit, die den gemischten Neurosen in Freuds Psychopathologie zukommt, die Rolle, die der diagnostische Prozess für die Rationalität der Psychoanalyse spielte.

Freud avec Charcot. La découverte de Freud et la question du diagnostic. Bien qu'on ait amplement mis en avant l'influence fondamentale que Charcot a exercée sur Freud et qu'on ait abondamment reconnu que le voyage de Freud à Paris pour suivre l'enseignement de Charcot a joué un rôle pivot dans le changement d'orientation de son travail qui l'a conduit de la neurologie à la psychopathologie, il n'en demeure pas moins qu'on ait largement sous-estimé un facteur clef de l'heuristique freudienne, à savoir que la découverte par Freud de la psychopathologie, qui a donné naissance à la psychanalyse, ne peut être séparée de sa "préoccupation diagnostique », qui constitue l'un des principes organisateurs fondamentaux - voire même le premier de ces principes à certains moments - de ses travaux les plus anciens. Cet article a donc pour visée de rouvrir la question du diagnostic en retraçant son développement le long du chemin qui mène de Charcot à Freud. Les auteurs montrent que dans l'attention minutieuse que Freud porte aux distinctions diagnostiques, il emboîte fidèlement le pas à la " méthode nosologique » de

\footnotetext{
$\overline{11 \text { "I I eventually found a way out of all these emerging doubts by the plan of treating all the other neuro- }}$ ses in question in the same way as hysteria. I determined to investigate their aetiology and the nature of their psychical mechanism in every case and to let the decision as to whether the diagnosis of hysteria was justified depend upon the outcome of that investigation" (Breuer and Freud, 1895, p. 256).
} 
Charcot. Les auteurs vont plus loin encore en cherchant à identifier précisément la façon dont les idées de ce dernier se retrouvent à l'œuvre dans le travail de Freud, afin de comprendre comment celui-ci les réinvestit pour forger son propre système nosologique. Les auteurs retracent donc le destin des leçons de Charcot dans l'œuvre de Freud et s'attachent à montrer que c'est l'importance attribuée aux névroses mixtes dans la psychopathologie freudienne qui leur permet de mettre en évidence le rôle joué par le processus diagnostique dans la logique psychanalytique.

Freud con Charcot. El Descubrimiento de Freud y la Cuestión del Diagnóstico. Aunque se afirma en general el papel seminal de Charcot en cuanto a su influencia en Freud, y aunque se reconoce que el viaje de Freud a París para estudiar con Charcot fue un punto de flexión para su giro desde el trabajo neurológico hacia lo psicológico, se sigue subestimando un hecho clave de la heurística freudiana: que el descubrimiento psicopatológico que dio origen al psicoanálisis no se puede separar de su 'preocupación diagnóstica', que constituye un principio crucial y por momentos el primer principio organizador de sus escritos más tempranos. El objetivo de los autores es por lo tanto re-abrir la cuestión del diagnóstico por medio de su seguimiento a lo largo del camino que va desde Charcot hasta Freud. Los autores demuestran que la atención minuciosa que le dedica Freud a las distinciones diagnósticas sigue estrictamente la dirección del 'método nosológico' de Charcot. Más importante aun, se proponen identificar el modo preciso en que sus ideas operan en el trabajo propio de Freud, para comprender de qué manera Freud los re-inviste para forjar su propio sistema nosológico. Al trazar las vicisitudes de las lecciones de Charcot en manos de Freud, es la importancia otorgada a las neurosis mixtas en la psicopatología de Freud que les permite a los autores precisar el papel del proceso diagnóstico en la racionalidad del psicoanálisis.

Freud con Charcot. La scoperta di Freud e la questione della diagnosi. Anche se si è ampiamente esaminato il ruolo determinante dell'influenza di Charcot su Freud, come pure è ben documentata l'importanza degli suoi studi parigini al fianco di Charcot nel passaggio dalla neurologia alla psicopatologia, c'è tuttavia un fattore chiave nell'euristica freudiana che viene ampiamente sottovalutato: ovvero che la scoperta di Freud della psicopatologica, che ha dato origine alla psicoanalisi, non può essere separata dalla sua 'preoccupazione diagnostica', che è un principio organizzante cruciale, a volte il primo, dei primi scritti. Questo lavoro intende riaprire la questione della diagnosi, seguendone il percorso evolutivo che da Charcot conduce a Freud. Gli autori dimostrano che l'accortezza e l'attenzione di Freud alle distinzioni diagnostiche seguono rigorosamente le direttive del 'metodo nosologico' di Charcot. In maniera ancora più significativa, l'articolo si propone di identificare il modo preciso in cui le idee di Charcot circolano nel lavoro di Freud, per comprendere come Freud le reinveste per forgiare il suo sistema nosologico. Se gli autori tracciano il destino delle lezioni di Charcot nell'elaborazione di Freud, è la sottolineatura dell'importanza delle nevrosi miste nella psicopatologia di Freud che veramente permette loro di individuare il ruolo che il processo diagnostico gioca nella razionalità psicoanalitica.

\section{References}

Altman M, Fitzpatrick-Hanly MA, Leuzinger-Bohleber M (2012). Panel reports: Project committee on clinical observation panels. Int J Psychoanal 93:748-50.

Arbeitskreis OPD, editor. (2006). Operationalisierte Psychodynamische Diagnostik OPD - 2. Das Manual für Diagnostik und Therapieplanung. Bern: Huber.

Breuer J, Freud S (1895). Studies on hysteria. SE 2.

Charcot JM (1881). Lectures on the diseases of the nervous system delivered at the Salpêtrière, 2nd series, Sigerson G, translator, editor. London: The New Sydenham Society.

Charcot JM (1888). Leçons du mardi à la Salpêtrière, vol. 1: 1887-1888. Paris: Lecrosnier et Babé \& Progrès médical.

Charcot JM (1889). Leçons du mardi à la Salpêtrière, vol. 2: 1888-1889. Paris: Lecrosnier et Babé \& Progrès médical.

Charcot JM (1891). Préface in: Levillain F (1891). La Neurasthénie. La maladie de Beard. Paris: Maloine.

Fonagy P, Gerber A, Kächele H, Krause R, Jones E, Perron R, Allison E (2002). An open door review of outcome studies in psychoanalysis. 2nd revised edn. London: IPA.

Freud S (1888). Hysteria. SE 1:41-57.

Freud S (1892). Preface and footnotes to the translation of Charcot's Tuesday lectures. SE 1:131-43.

Freud S (1893). Charcot. SE 3:7-23.

Freud $S$ (1894a). On the grounds for detaching a particular syndrome from neurasthenia under the description 'anxiety neurosis'. SE 3:85-115.

Freud S (1894b). The neuro-psychoses of defence. SE 3:41-61. 
Freud S (1894c). Obsessions and phobias. SE 3:69-82.

Freud S (1896a). Heredity and the aetiology of the neuroses. SE 3:141-56.

Freud S (1896b). Extracts from the Fliess papers. Draft K. SE 1:220-83.

Freud S (1896c). Further remarks on the neuro-psychoses of defence. SE 3:157-85.

Freud S (1898). Sexuality in the aetiology of the neuroses. SE 3:259-85.

Freud S (1906). Preface to Freud's shorter writings 1893-1906. SE 3:1-6.

Freud S (1912). Recommendations to physicians practising psycho-analysis. SE 12:109-20.

Freud S (1913). The claims of psycho-analysis to scientific interest. SE 13:163-90.

Freud S (1915-16). Introductory lectures on psycho-analysis(Parts 1 and 2). SE 15.

Freud S (1916-17). Introductory lectures on psycho-analysis (Part 3). SE 16.

Freud S (1917). Mourning and melancholia. SE 14:237-58.

Freud S (1919). Lines of advance in psycho-analytic therapy. SE 17:157-68.

Freud S (1926). Inhibitions, symptoms and anxiety. SE 20:75-176.

Freud S (1933). New introductory lectures on psycho-analysis. SE 22.

Freud S (1970). Letters of Sigmund Freud 1873-1939. London: Hogarth.

Freud S (1987). Wiener medizinisches Doktorenkollegium Sitzung vom Oktober 1895: 'Über Hysterie'. GW, Nachtr.

Janet P (1895). J.-M. Charcot: son œuvre psychologique. Rev Philos France et de l'Étranger 39:569604.

Jones E (1956). Sigmund Freud: Life and work, vol. 1: The young Freud. London: Hogarth.

Levillain F (1891). La Neurasthénie. La maladie de Beard. Paris: Maloine.

Luyten P, Blatt S, Corveleyn J (2006). Minding the gap between positivism and hermeneutics in psychoanalytic research. J Am Psychoanal Assoc 54:571-610.

Miller JA, Sabshin M, Gedo J, Pollock G, Sadow L, Schlessinger N (1969). Some aspects of Charcot's Influence on Freud. J Am Psychoanal Assoc 17:608-23.

PDM (2006). Psychodynamic diagnostic manual. Silver Spring, MD: Alliance of Psychoanalytic Organizations.

Villa F (2007). Les névroses mixtes: une leçon de méthode nosographique. L'Évolution psychiatrique 72:477-87. 